\title{
A CRISE AMBIENTAL GLOBAL: CONJUNTURA E INTERPRETAÇÕES
}

\author{
Vanderlei de Oliveira Ferreira \\ Universidade Federal de Uberlândia - UFU \\ Professor Doutor, Instituto de Geografia \\ vanderlei.ferreira@ufu.br \\ Rafael Mendes Rosa \\ Universidade Federal de Uberlândia - UFU \\ Doutorando, Instituto de Geografia \\ rafaelmendesr@hotmail.com
}

\begin{abstract}
RESUMO
Fenômenos naturais e/ou induzidos pela ação econômica, amplamente reconhecidos e estudados por diversas áreas do conhecimento científico, colocam em risco a segurança e a vida das diferentes formas de vida do planeta Terra. Dentre os principais conjuntos de problemas ambientais reconhecidos, que preocupam a comunidade científica e a maioria dos gestores, destacam-se aqueles relacionados à urbanização acelerada e omissa em relação às variáveis ambientais, aos distúrbios diretamente atinentes ao funcionamento dos ecossistemas (desmatamento e defaunação), às alterações nos aspectos qualiquantitativos da água, às perturbações físicas e químicas aos oceanos e ao aquecimento global e mudanças climáticas. A politização e ideologização, bem como o debate teóricoconceitual em torno da crise ambiental instalada, implicam em perspectivas comportamentais peculiares, métodos e metodologias específicos para entender e agir. Isso impulsiona debates públicos, porém pode ocasionar estagnação de ações gerenciais. $O$ presente texto discute a conjuntura atual da crise ambiental e apresenta as concepções de quatro grupos que a interpretam de formas muito distintas: os nelmalthusianos, os cornucopianistas, os marxistas e os ecodesenvolvimentistas.
\end{abstract}

Palavras-chave: Debate teórico-conceitual. Nelmalthusianismo. Cornucopianismo. Marxismo. Ecodesenvolvimentismo.

\section{THE GLOBAL ENVIRONMENTAL CRISIS: CONJUNCTURE AND INTERPRETATIONS}

\begin{abstract}
Natural phenomena and/or induced by economic action, widely recognized and studied by several areas of scientific knowledge, put the safety and life of the different forms of life on planet Earth at risk. Among the main sets of recognized environmental problems, which concern the scientific community and the majority of managers, those related to accelerated and silent urbanization in relation to environmental variables, disturbances directly related to the functioning of ecosystems (deforestation and defaunation), changes in the qualitative and quantitative aspects of water, physical and chemical disturbances to the oceans and global warming and climate change stand out. Politicization and ideologization, as well as the theoretical-conceptual debate surrounding the installed environmental crisis, imply peculiar behavioral perspectives, specific methods and methodologies to understand and act. This stimulates public debates, but generates stagnation in managerial actions. This text discusses the current situation of the environmental crisis and presents the concepts of four groups that interpret it in very different ways: the nelmalthusians, the cornucopianists, the marxists and the ecodevelopmentists.
\end{abstract}

Keywords: Theoretical-conceptual debate. Nelmalthusianism. Cornucopianism. Marxism. Eco-developmentism.

\section{INTRODUÇÃO}

A crise ambiental global submete a humanidade aos impactos de manifestações de fenômenos diversos e cria situações de instabilidades e incertezas que exigem ações individuais e coletivas para que seja superada ou, pelo menos, minimizada. A aceitação da existência desta crise ambiental global ampara-se em dados e informações produzidos por diversas áreas do conhecimento científico. As pesquisas demonstram que a ação econômica sobre o meio ambiente gera danos variados ao

\begin{tabular}{|c|}
\hline aminhos de Geografia Uberlândia \\
\hline
\end{tabular}


bem-estar humano e trazem incertezas quanto à permanência das condições de habitabilidade do planeta.

Genericamente, as estratégias adotadas diante de tal crise têm reunido comportamentos de acomodação ou de proatividade. As ações de acomodação dizem respeito ao não reconhecimento da existência da crise ou acusações de culpa a outros sujeitos. São marcadas pela negação de possíveis atitudes de compensações e/ou de recuperações dos danos ambientais.

As ações proativas propõem antecipar iniciativas preventivas e efetivas para a resolução ou minimização dos problemas que se manifestam em variadas escalas temporais e espaciais. Indivíduos e organizações procuram agir de maneira preventiva e/ou corretiva, auxiliando na construção de soluções comportamentais e tecnológicas, sempre almejando evitar ou minimizar a consumação de desastres maiores.

O presente texto procura expor as circunstâncias da existência de uma crise ambiental e apresenta as principais interpretações presentes nas discussões a respeito, incluindo possíveis desdobramentos relacionados à adoção das diferentes perspectivas.

\section{CONJUNTURA DA CRISE AMBIENTAL GLOBAL}

Dentre os principais problemas ambientais que preocupam a comunidade científica e a maioria dos gestores, destacam-se aqueles relacionados à urbanização acelerada e omissa em relação às variáveis ambientais, distúrbios diretamente atinentes ao funcionamento dos ecossistemas (desmatamento e defaunação), alterações nos aspectos quali-quantitativos da água, perturbações físicas e químicas aos oceanos, aquecimento global e mudanças climáticas. Aspectos sinérgicos e amplamente dinâmicos exigem esforços quanto à compreensão sistêmica de tais problemas.

\section{Urbanização acelerada e omissa em relação às variáveis ambientais}

A concentração de população em áreas urbanas deu origem a várias metrópoles com mais de 15 milhões de habitantes no mundo, que demandam grandes quantidades de energia e recursos naturais destinados à infraestrutura e consumo, além de provocarem impactos ambientais diretos ao clima, biodiversidade e às águas. Os cenários são muito diversificados, havendo cidades em situações muito distintas. Normalmente a precariedade do processo potencializa os impactos ambientais, principalmente nas grandes metrópoles de países não desenvolvidos, onde os problemas de organização e ineficiência do planejamento urbano são mais evidentes.

Para Rodrigues (2011), a urbanização acelerada está associada a um planejamento urbano ausente ou ineficaz. Nesse contexto, o sistema de saneamento básico é desconsiderado, gerando grandes volumes de esgoto doméstico sem destinação adequada, o que pode gerar doenças diversas. A disposição inadequada de resíduos sólidos, tanto inertes quanto tóxicos, traz problemas não somente de saúde pública, mas também ao ambiente urbano de modo geral, pois de alguma forma acabam afetando as águas, solos e ar, além de servirem de ambiente para reprodução de vetores causadores de doenças. Ademais, o transporte público deficiente em grandes metrópoles de países subdesenvolvidos força parte da população a adotar o transporte individual como alternativa à mobilidade urbana, acarretando problemas de qualidade de vida devido a congestionamentos e poluição do ar e sonora.

A figura 1 mostra a tendência de evolução da população urbana em detrimento da rural no mundo. Até o ano de 2050 quase 7 bilhões de pessoas estarão vivendo em cidades (a). Este fenômeno de concentração urbana ocorre de forma diferenciada entre os países, havendo situações muito distintas (b). É necessário que os planejadores e gestores do espaço urbano procurem mitigar os impactos ambientais para uma maior qualidade de vida da população e respeito às variáveis físico-ambientais. 
Figura 1 - Evolução da população urbana em detrimento da rural no mundo (a) e evolução da população urbana em alguns países (b)

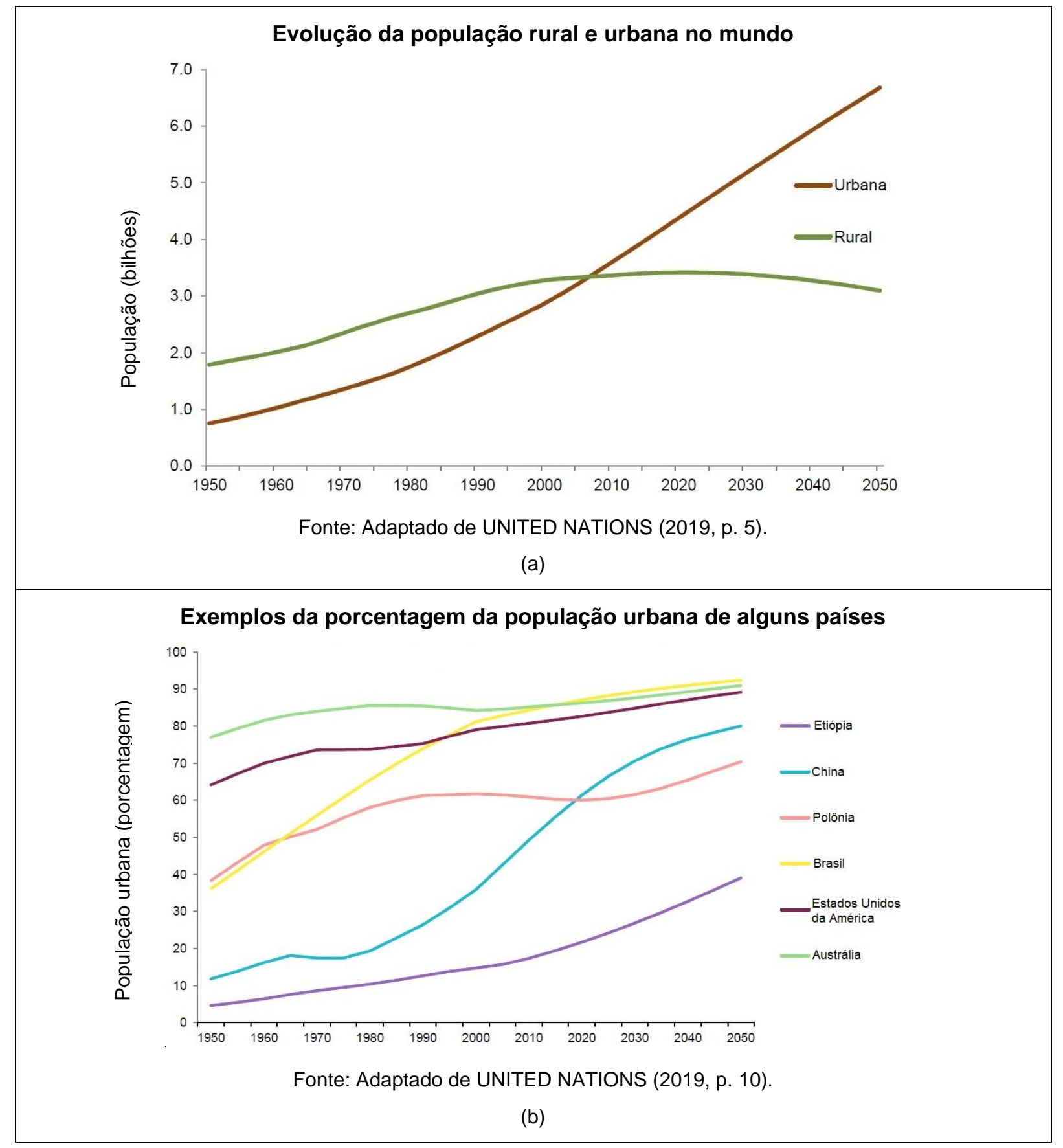

\section{Distúrbios ao funcionamento dos ecossistemas terrestres (desmatamento e defaunação)}

A agricultura, reflorestamento e pecuária ocupam grandes extensões de terra em regime de monocultura, podendo gerar intensificação de processos erosivos, interferências na dinâmica hídrica e drástica homogeneidade genética. Há intenso desmatamento e queimadas especialmente nas florestas tropicais, podendo eliminar rapidamente os remanescentes de vegetação nativa do planeta. A implantação de projetos de recuperação de faixas marginais dos cursos d'água e reservas ambientais e a refaunação é urgente como forma de reduzir o processo de destruição e restabelecimento de relações ecológicas perdidas. A figura 2 ilustra o desmatamento do território brasileiro nos biomas amazônico (a) e cerrado (b). Esse último já foi amplamente desmatado no passado, restando fragmentos pouco representativos para qualidade ambiental, como áreas legalmente protegidas nem sempre realmente protegidas.

$\begin{array}{llllll}\text { Caminhos de Geografia } & \text { Uberlândia - MG } & \text { v. 22, n.84 } & \text { dez/2021 } & \text { p. 187-199 } & \text { Página } 189\end{array}$


Figura 2 - Taxas de desmatamento nos biomas Amazônia (a) e Cerrado (b)

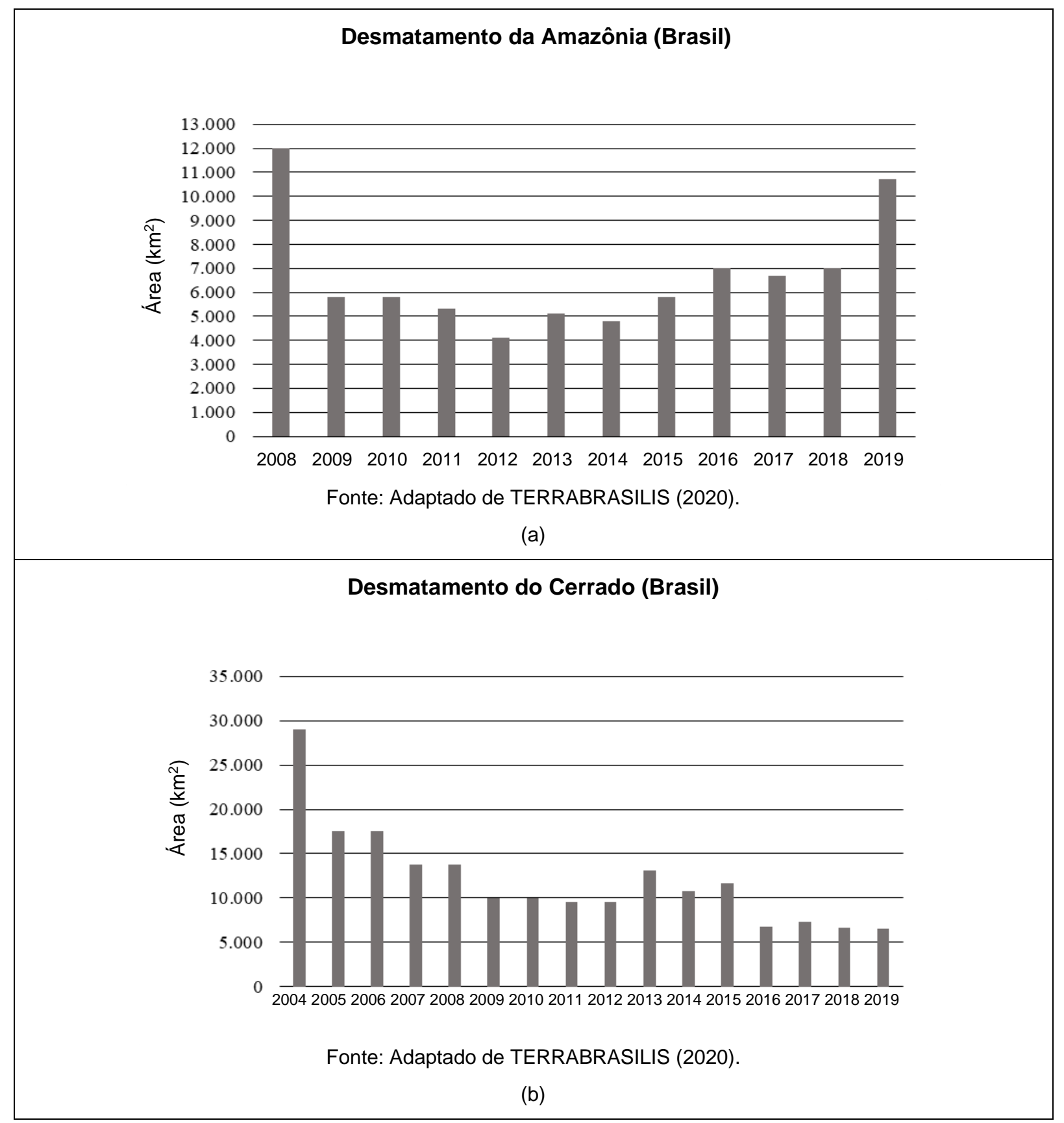

\section{Alterações nos aspectos quali-quantitativos da água}

O consumo de água é muito desigual no mundo. Enquanto um cidadão estadunidense consume próximo de 600 litros/dia, um etíope ou haitiano consome apenas 15 litros/dia. $\mathrm{O}$ tratamento de esgoto é deficiente em grande parte do mundo e a poluição proveniente da indústria e agricultura impactam negativamente a qualidade da água superficial e subterrânea, restringindo a disponibilidade hídrica para inúmeros usos. Algumas regiões do globo apresentam restrições hídricas de origem física e em outras a escassez está associada às relações econômicas e opções gerenciais. No Brasil, país representativo para essa questão, a retirada de água para atender às diversas finalidades ainda tende a se intensificar, sobretudo para irrigação. Além disso, enquanto pouco mais de $80 \%$ da população é atendida com água tratada, os danos quali-quantitativos ainda são um grande desafio, pois o percentual de coleta e tratamento de esgoto ainda é relativamente baixo e a perda no processo de distribuição é significativa. A figura 3 mostra dados de captação e consumo da água pelos principais setores usuários no mundo (a) e também informações sobre saneamento no Brasil (b).

\begin{tabular}{llllll}
\hline Caminhos de Geografia & Uberlândia - MG & v. 22, n.84 & dez/2021 & p. 187-199 Página 190
\end{tabular}


Figura 3 - Distribuição dos volumes de água captados e efetivamente consumidos no mundo pelos setores industrial, agrícola e de abastecimento (a) e informações sobre saneamento básico no Brasil (b)

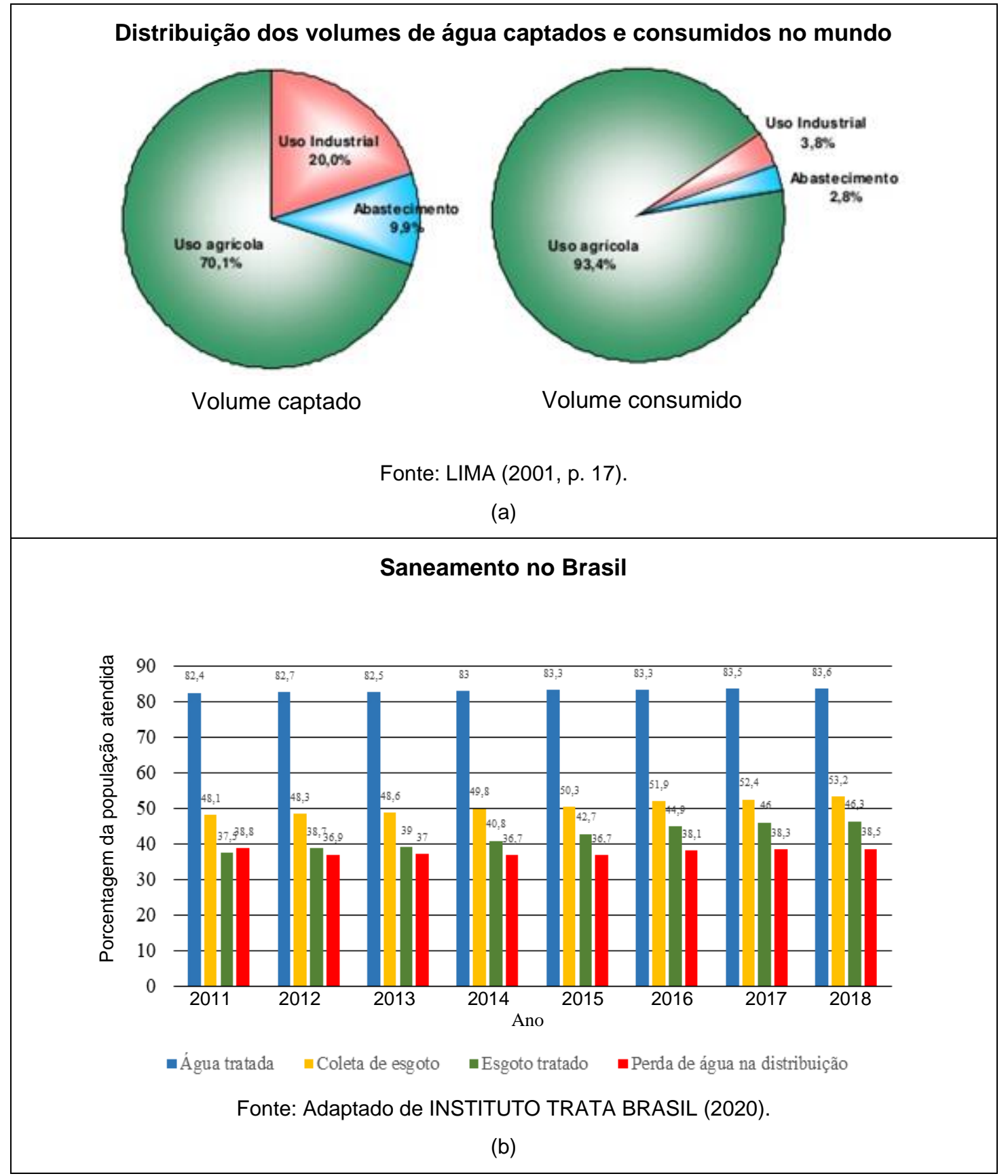

\section{Perturbações físicas e químicas aos oceanos}

Os oceanos são muito importantes em termos hidrológicos, ecológicos e climáticos. Os fenômenos oceânicos interagem fortemente com a atmosfera, interferindo na dinâmica dos eventos climáticos em várias escalas têmporo-espaciais. A este respeito, Pezzi et al. (2015) destacam que a "importância do Oceano Atlântico Sul para o clima do planeta está cada vez mais clara através de pesquisas recentes que avaliam a contribuição desse oceano para a circulação termohalina global através da chamada Célula de Revolvimento Meridional do Atlântico (CRMA)". Na verdade, o clima do planeta é fortemente influenciado pelas interações oceano-atmosfera.

Resultados de várias pesquisas indicam alterações químicas nos oceanos em decorrência do aumento de $\mathrm{CO}_{2}$ atmosférico. A crescente dissolução de $\mathrm{CO}_{2}$ forma ácido carbônico e,

$\begin{array}{llllll}\text { Caminhos de Geografia } & \text { Uberlândia - MG } & \text { v. 22, n.84 } & \text { dez/2021 } & \text { p. 187-199 Página } 191\end{array}$


consequentemente, provoca acidificação das águas. Tal fenômeno causa impactos à biota e à própria dinâmica de interação química oceano-atmosfera. Além disso, várias pesquisas têm indicado alterações térmicas e também no volume oceânico, incluindo elevação nos níveis altimétricos das águas (figura 4).

Figura 4 - Concentração de $\mathrm{CO}_{2}$ e acidificação (a), incremento energético (b) e alteração do nível dos oceanos (c)

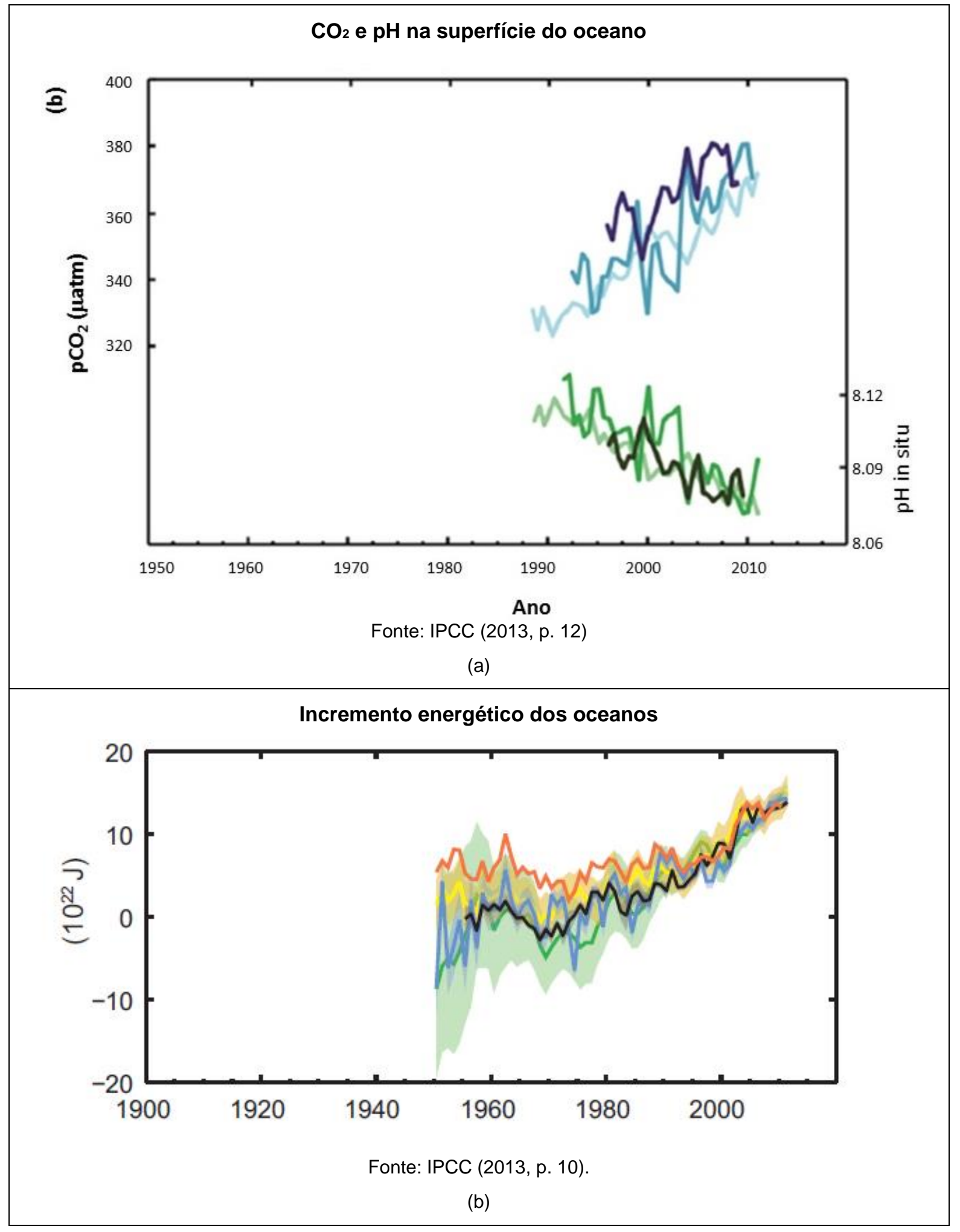




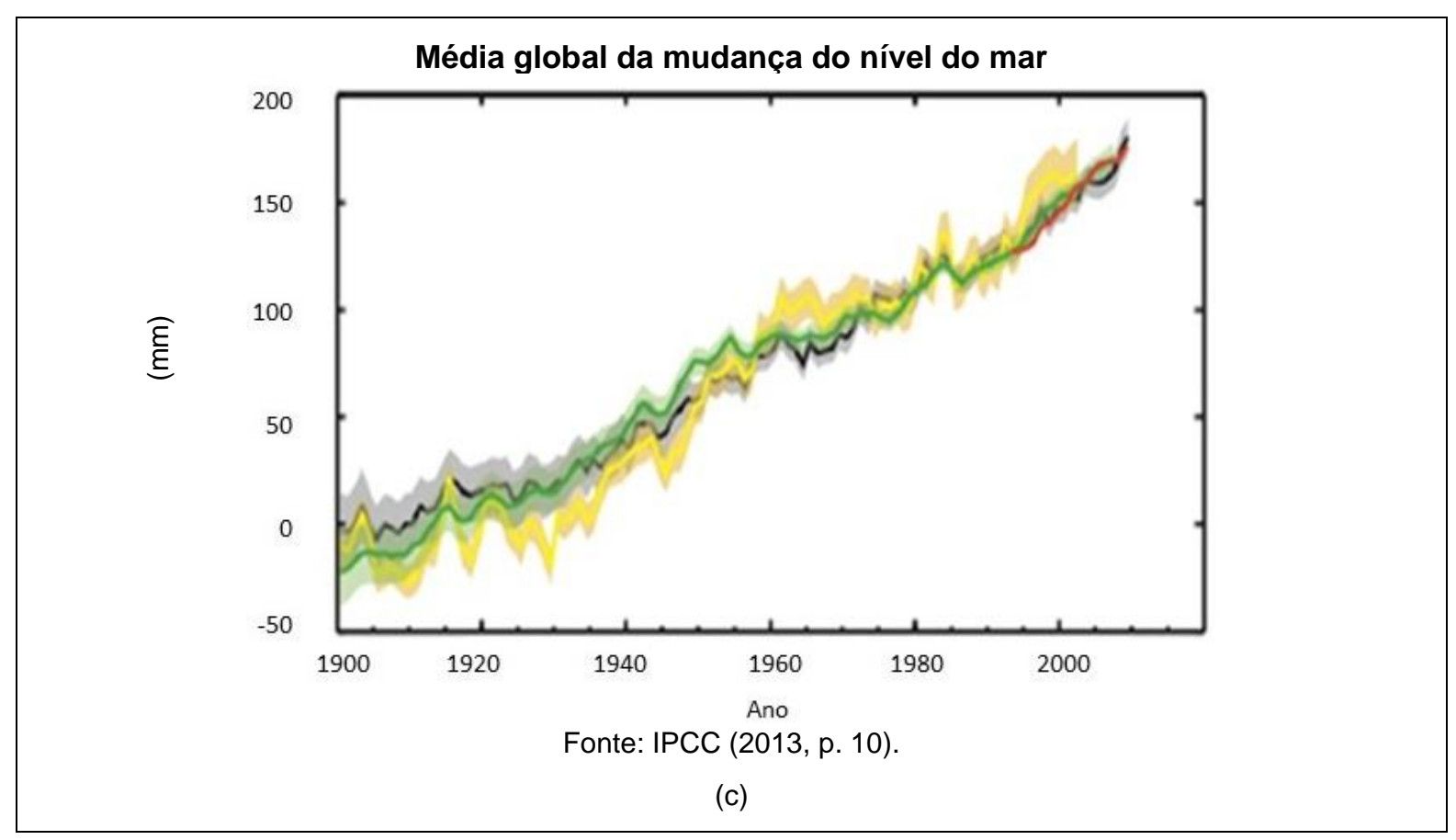

\section{Aquecimento global e mudanças climáticas}

As atividades econômicas têm provocado elevação da média de temperatura em escala global, bem como um quadro de mudanças climáticas que repercute nas escalas inferiores. As pesquisas das mais renomadas agências, institutos e universidades do mundo buscam análises prognósticas cada vez mais refinadas. Nesse contexto, a Organização Meteorológica Mundial (OMM) e o Programa das Nações Unidas para o Meio Ambiente (PNUMA) criaram, em 1988, o Painel Intergovernamental sobre Mudanças Climáticas (IPCC) com o objetivo de apoiar trabalhos científicos, avaliações sobre o clima e prognosticar cenários de mudanças climáticas (AMBRIZZI et al., 2007). São utilizados como ferramentas os Modelos de Circulação Geral (MCG), sendo os mais sofisticados aqueles que consideram em totalidade o oceano, como os Modelos de Circulação Geral Atmosfera-Oceano (MCGAO).

Os relatórios do IPCC, amparados pelos resultados da aplicação de modelagens, projetam cenários reunidos em 4 grupos denominados de "Special Report on Emissions Scenarios (SRES) que consideram diferentes projeções de emissões de gases de efeito estufa, relacionados com características do meio ambiente, crescimento econômico, questões tecnológicas e crescimento populacional (NAKICENOVIC et al., 2000).

Para a América do Sul os modelos indicam que as mudanças climáticas mais intensas para o final do século XXI irão ocorrer na região intertropical, mais especificamente no Peru, Equador, Amazônia e no Nordeste do Brasil. A figura 5 apresenta a evolução da temperatura global (média anual) nos últimos 170 anos, considerando causas naturais e humanas e simulação considerando apenas causas naturais (a) e a espacialização do processo de aquecimento acumulado desde o início do século XX segundo diferentes cenários de incremento térmico (b). Importante salientar que a superfície terrestre apresentou nas três últimas décadas temperaturas mais quentes do que em qualquer década após 1850. 
Figura 5 - Evolução da temperatura global (média anual) observada e simulada para os últimos 170 anos (a) e mudanças na temperatura média global da superfície da Terra e dos oceanos a partir de 1850-1900, considerando três cenários distintos (b)

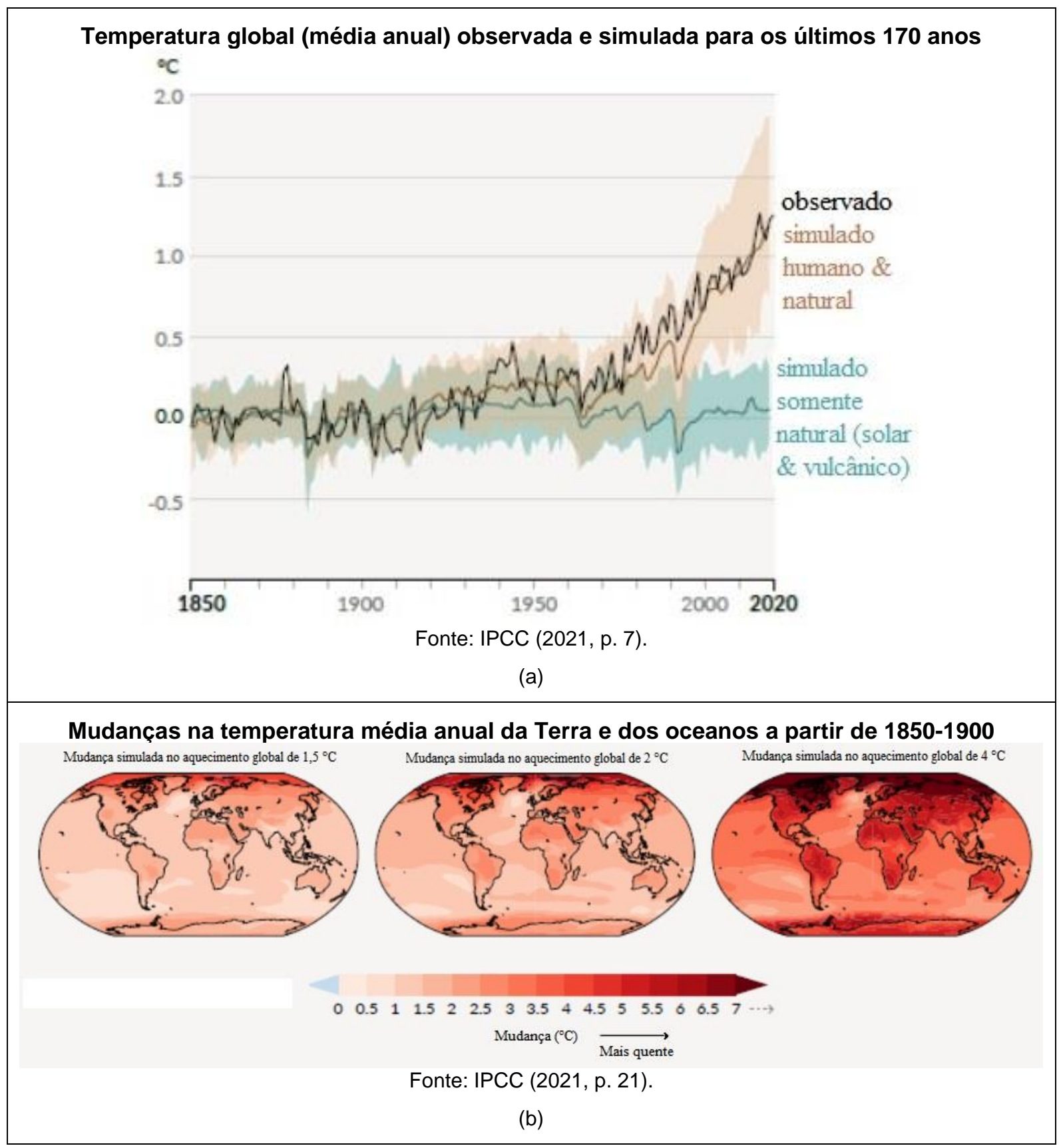

\section{INTERPRETAÇÕES ACERCA DA CRISE AMBIENTAL GLOBAL}

Concepções teórico-metodológicas e grupos com diferentes identidades políticas têm visões específicas de mundo e, portanto, concepções diferenciadas acerca da crise ambiental. Isso implica em perspectivas comportamentais peculiares, métodos e metodologias específicos para entender e agir. No presente texto serão apresentadas as concepções de quatro grupos que interpretam a crise ambiental de formas muito distintas.

\section{Nelmalthusianos}

Em 1798, mediante publicação da obra "An Essay on the Principle of Population", o economista iluminista Thomas Malthus constituiu as premissas da análise integrada e determinista da relação entre crescimento populacional não planejado e disponibilidade limitada de recursos naturais. As

$\begin{array}{llllll}\text { Caminhos de Geografia } & \text { Uberlândia - MG } & \text { v. 22, n.84 } & \text { dez/2021 } & \text { p. 187-199 Página } 194\end{array}$


ideias de Malthus (1983) conduziram à concepção mais recente de que a reprodução limitada dos recursos naturais e o descarte inadequado de resíduos conduzirá a humanidade a uma inevitável catástrofe ambiental e colapso econômico.

Os Nelmalthusianos, que reelaboraram as ideias de Malthus a partir do início do século XX, acreditam que a humanidade está condenada à infelicidade. “... acreditavam, e ainda acreditam, que o mundo já está superpovoado e, portanto, condenado ao desastre, seja pela exaustão dos recursos naturais esgotáveis, seja pela excessiva sobrecarga de poluentes aos sistemas de sustentação da vida" (SACHS, 1993).

A obra "Os Limites do Crescimento", publicada em 1972 pelo chamado Clube de Roma, com a participação de Donella H. Meadows, Dennis L. Meadows, Jorgen Randers e William W. Behrens é considerada a referência fundamental da concepção nelmalthusiana. Os autores utilizaram pioneiramente um sistema computacional para prognosticar as consequências da interação desequilibrada entre a crescente população humana e os sistemas naturais, considerando cinco variáveis: população mundial, industrialização, poluição, produção de alimentos e esgotamento de recursos naturais. Mais recentemente, Meadows, Randers e Meadows (2004), após atualizar os dados da primeira publicação e aprimorar a análise, afirmaram confirmar os resultados apontados na versão original.

O prognóstico nelmalthusiano é sombrio: "Colapso ecológico, originado pela depleção dos recursos naturais e a mudança do clima global"; "Falta de energia, devido ao esgotamento do petróleo e do gás"; e "perda da estabilidade econômica provocada pela dívida norte-americana e um complexo e insustentável sistema financeiro internacional". O gráfico da figura 6 mostra o resultado original da aplicação do modelo computadorizado pelo Clube de Roma em 1972 (versão traduzida em 1973). As variáveis nele consideradas ainda são centrais nas discussões referentes à crise ambiental na atualidade.

Figura 6 - Gráfico resultante do processamento padrão do modelo computadorizado do Clube de Roma

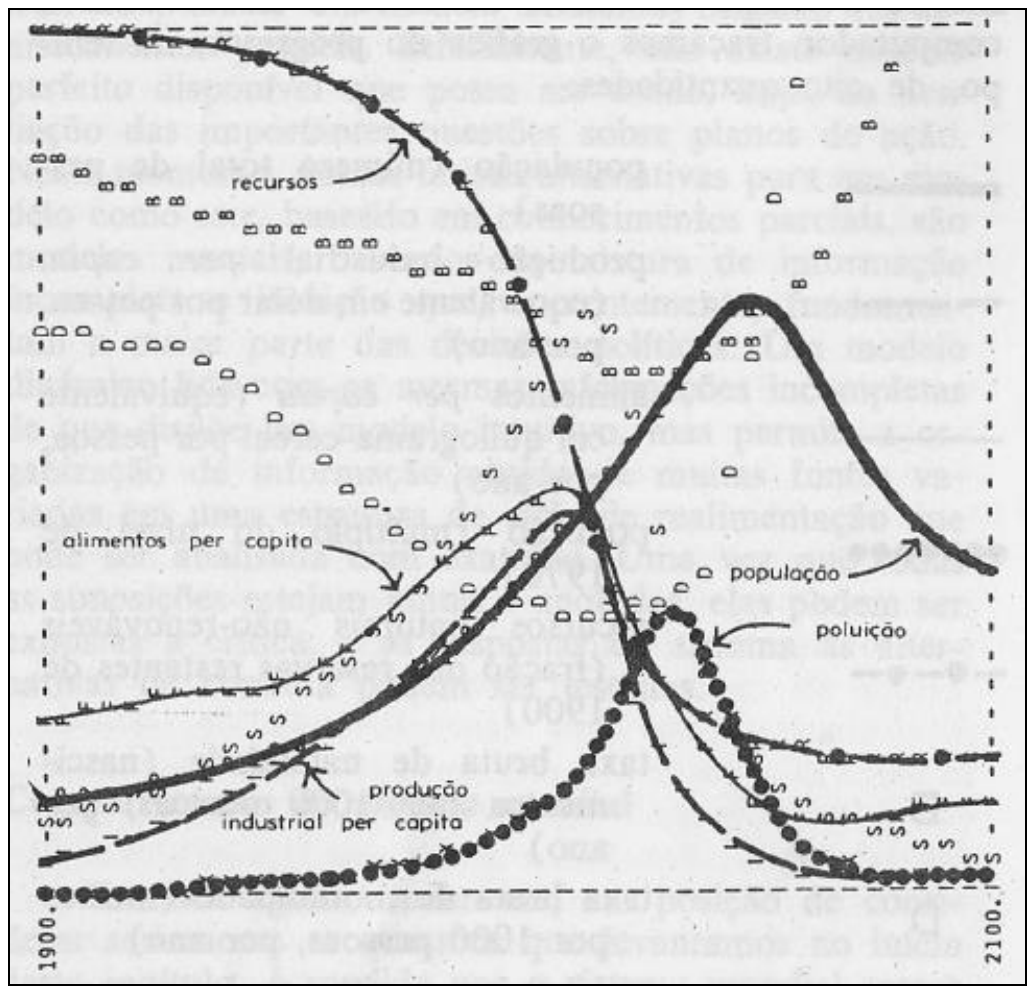

Fonte: MEADOWS et al. (1973, p. 122).

\section{Cornucopionistas}

O termo Cornucópia surgiu em referência à cabra Amalteia, que cedeu leite a Zeus, garantindo-Ihe a sobrevivência quando recém-nascido. Quando Zeus tornou-se rei dos deuses, agradeceu ao

$\begin{array}{llllll}\text { Caminhos de Geografia } & \text { Uberlândia - MG } & \text { v. 22, n.84 } & \text { dez/2021 } & \text { p. 187-199 Página } 195\end{array}$


gesto gentil concedendo especial poder aos chifres de Amalteia. Aqueles que os possuíssem poderiam ter tudo que desejassem.

$\mathrm{Na}$ verdade, a ideia de abundância ilimitada dominou a humanidade durante sua história. Todas as atividades e materialidades construídas sempre foram vistas enquanto símbolos de abundância e progresso eterno. Tal concepção, hegemônica nos padrões comportamentais de ampla maioria da população ainda nos dias atuais, demonstra a disposição humana para converter infinitamente a natureza em produtos para atender suas necessidades ou pura ambição.

O cornucopianismo subsidia e sustenta a perspectiva materialista ilimitada da economia clássica e partidos políticos conservadores atuais, em contraposição aos preceitos presentes nos movimentos ecológicos, vinculados a perspectivas conservacionistas baseadas na expectativa de suficiente atendimento das necessidades humanas. "Os cornucopianos confiam na capacidade de superar a escassez física e as consequências deletérias do lançamento de dejetos na biosfera por meio do ajuste tecnológico" (SACHS, 1993).

Diamandis e Kotler (2012) afirmam que "a tecnologia é capaz de fazer brotar a abundância, manter o crescimento exponencial e democratizar o bem-estar". Nesse caso, acredita-se que os processos produtivos possam ser alterados por meio da adoção de novas tecnologias, capazes de reverter ou evitar impactos ambientais extremos. A poluição/degradação cessaria e a renda per capta continuaria a subir (figura 7).

Figura 7 - Gráfico da ocorrência de degradação mediante processo de crescimento da renda per capta (Curva de Kuznets)

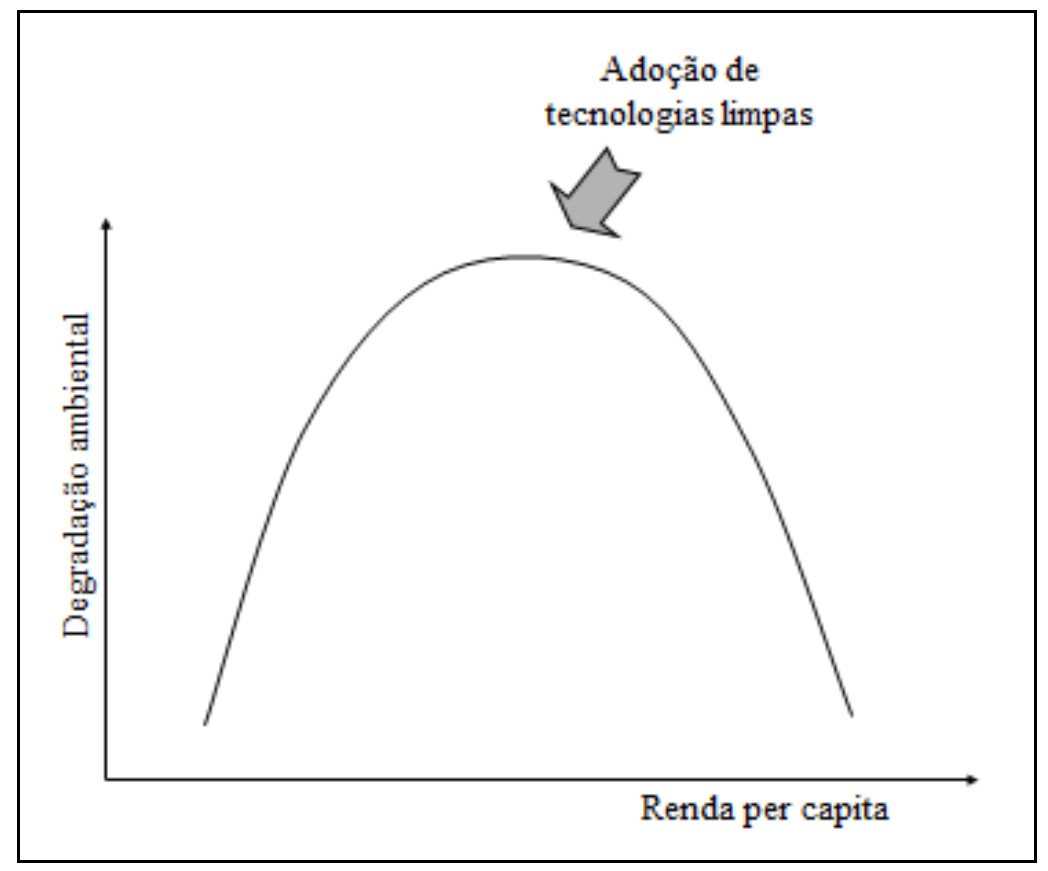

Fonte: Adaptado de LOMBORG (2002).

\section{Marxistas}

No contexto histórico da obra de Marx a degradação da natureza não era assunto de destaque. Marx dedicou-se principalmente à discussão acerca da exploração da força de trabalho, embora haja extensa produção bibliográfica colocando-o enquanto precursor do ambientalismo atual. $\mathrm{Na}$ concepção atual dos marxistas e marxólogos, os responsáveis pela crise ambiental representam parcelas específicas da sociedade, que se apropriam privadamente e inadequadamente dos recursos naturais.

Para Foladori (1997, p.146) "... a origem da crise ambiental está no tipo de relações sociais de produção adotado pela sociedade. A crise ecológica como extensão da crise do capitalismo". Nesse caso, as classes sociais situadas na base da pirâmide da riqueza não são culpadas pelos problemas ambientais, mesmo porque não conseguem acessar ao consumo de necessidades básicas para sobrevivência digna. "Em situações de extrema pobreza, o indivíduo marginalizado da sociedade e da

\begin{tabular}{llllll}
\hline Caminhos de Geografia & Uberlândia - MG & v. 22, n.84 & dez/2021 & p. 187-199 & Página 196
\end{tabular}


economia nacional não tem nenhum compromisso para evitar a degradação ambiental, uma vez que a sociedade não impede sua própria degradação como pessoa" (GUIMARÃES, 1991, p. 17).

Para os marxistas, a sustentabilidade ambiental, entendida enquanto conciliação entre produção material ilimitada, bem-estar social e dinâmica da natureza, é impossível diante do contexto sociopolítico atual. Para eles, a crise ambiental e o processo de automação ameaçam a permanência do capitalismo. A permanência e o futuro da humanidade dependeriam, portanto, de soluções para essas duas questões sobrepostas.

\section{Ecodesenvolvimentistas}

Foi diante das ameaças da crise ambiental que surgiu, na década de 1970 , o conceito e ecodesenvolvimentismo, substituído nos anos de 1980 pelo desenvolvimento sustentável, sem alterações significativas na concepção original. Basicamente, trata-se de um propósito alternativo de desenvolvimento que supostamente atenderia as necessidades do presente, sem comprometer a sobrevivência das futuras gerações. Os ecodesenvolvimentistas defendem um equilíbrio entre crescimento econômico, preservação da natureza e o bem-estar social amplo (figura 8).

Figura 8 - Dimensões da sustentabilidade

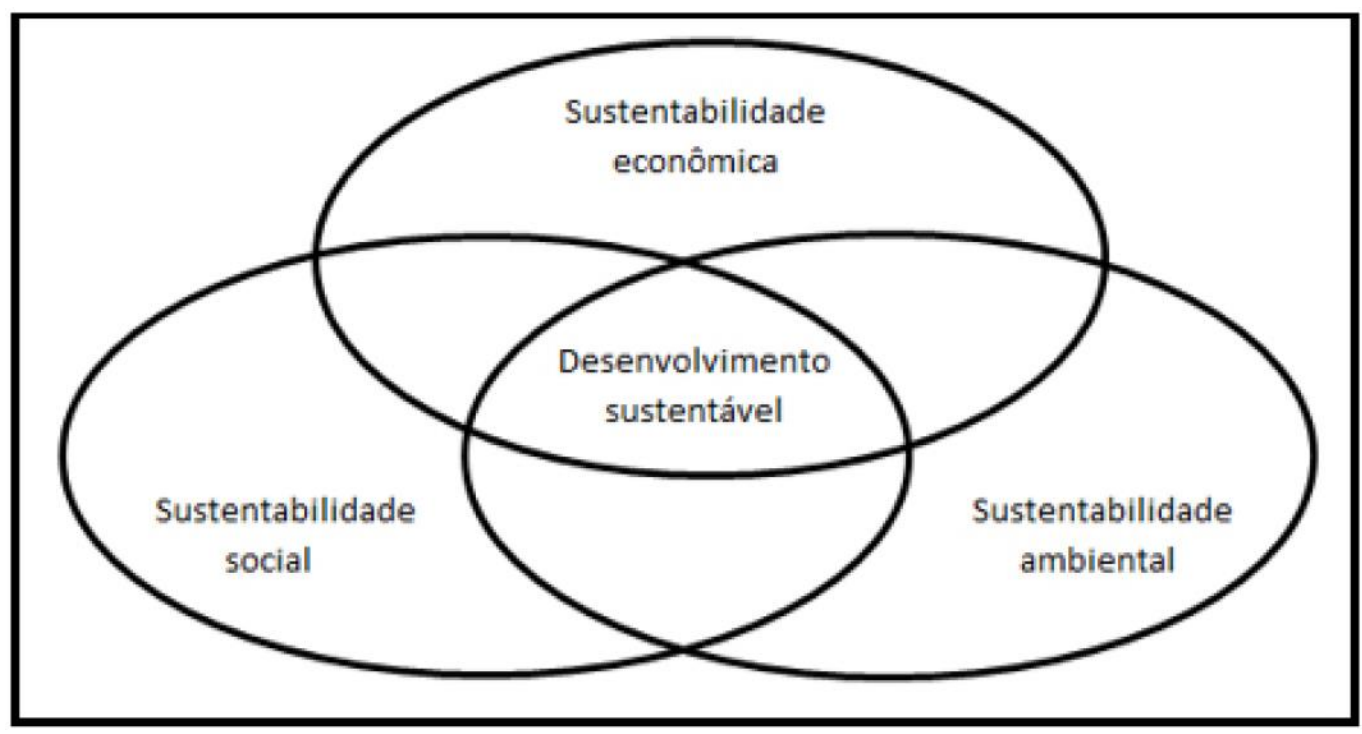

Fonte: BARBIERI e CAJAZEIRA (2012, p. 68).

Trata-se de uma proposição conciliadora na medida em que sugere superar as divergências entre neomalthusianos, cornucopianistas e marxistas. Entretanto, tais correntes criticam as proposições ecodesenvolvimentistas. Os neomalthusianos e marxistas apontam a manutenção dos riscos de perdas ambientais importantes e irreversíveis e apresentam várias questões ainda não respondidas, dentre as quais: É possível o crescimento infinito com recursos naturais finitos? É possível a expansão global do atual padrão de consumo daqueles que estão no topo da pirâmide social? A ciência e a tecnologia garantirão a superação de todos os desafios? A "mão invisível do mercado" é capaz de produzir equidade sem conflitos? Críticas são especialmente dirigidas à submissão do termo à racionalidade econômica, considerando ser impossível construir relações de cooperação num mundo extremamente competitivo.

$\mathrm{Na}$ verdade, o termo "desenvolvimento sustentável" permanece extremamente polissêmico. Diferentes significados são empregados de acordo com diferentes interesses e contextos. Percebe-se uma banalização da expressão e seu uso frequentemente equivocado e/ou indevido. Permanecem desafios aparentemente insuperáveis diante da necessidade de novos valores, novas estratégias produtivas, novos comportamentos e uma base ética verdadeiramente compromissada com vida digna para todos.

$\begin{array}{llllll}\text { Caminhos de Geografia } & \text { Uberlândia - MG } & \text { v. 22, n.84 } & \text { dez/2021 } & \text { p. 187-199 } & \text { Página } 197\end{array}$


O desenvolvimento sustentável, entretanto, é a única corrente que apresentou propostas efetivas e instrumentais de planejamento e gestão ambiental exatamente porque foi amplamente aceita por governos e empreendedores privados. No Brasil, por exemplo, na lógica do desenvolvimento sustentável, a Política Nacional do Meio Ambiente (Lei n 6.938, de 31 de agosto de 1981) propôs instrumentos para minimizar os impactos ambientais decorrentes das atividades produtivas. $O$ zoneamento e o licenciamento ambiental são exemplos de instrumentos propostos pela Política Nacional do Meio Ambiente no Brasil. Aliás, foi por meio da aceitação das premissas do desenvolvimento sustentável que diversos países adotaram estratégias de planejamento e gestão ambiental.

\section{CONCLUSÔES}

As divergências conceituais, teóricas, políticas e ideológicas em torno da crise ambiental impulsionam pesquisas e debates, porém geram estagnação de ações. Enquanto isso, os desafios da crise se mostram resilientes. Eventos climáticos extremos e distúrbios relacionados ao funcionamento dos ecossistemas tais como as epidemias são cada vez mais frequentes e intensos.

A Ciência Física indica a impossibilidade de incrementos infinitos na eficiência de sistemas reais. Assim, é impossível acreditar que a tecnologia permitirá crescimento econômico infinito. Permanece a necessidade de uma concepção de desenvolvimento que ponha realmente as pessoas em primeiro lugar, que aposte nas possibilidades de dignificação da pessoa humana, porém em um contexto de respeito à natureza. É preciso superar conceitos e perspectivas que guardam altas doses de subjetividade, sendo adotados de formas diferenciadas e ideologizados conforme os diversos interesses.

A implementação de uma nova perspectiva requer redirecionamento político em todos os níveis. A tarefa que se impõe é escolher as melhores alternativas para atender aos anseios de justiça social e melhoria da qualidade de vida, amenizando os impactos das externalidades negativas da ação econômica sobre o meio ambiente. Há ideias dispersas e utópicas, diversificadas e às vezes antagônicas. É evidente que a construção de um modelo alternativo e sustentável de relação homem/natureza avançou diante da implantação de instrumentos de planejamento e gestão nas últimas décadas, mas ainda precisa ser construído a cada dia.

A perspectiva do desenvolvimento sustentável é a mais difundida atualmente e parece receber maior aceitação. Mas ela também ainda está em construção. Não há uma concepção consensual de seus princípios. Enquanto isso, agências, institutos de pesquisa e universidades renomadas do mundo inteiro evidenciam incessantemente a crise ambiental no planeta, incluindo a exaustão de recursos naturais essenciais, ocorrência de pandemias e limitações à sobrevivência dos seres vivos.

\section{AGRADECIMENTOS}

O segundo autor agradece à Coordenação de Aperfeiçoamento de Pessoal de Nível Superior (CAPES) pela concessão da bolsa de doutorado.

\section{REFERÊNCIAS}

AMBRIZZI, T.; ROCHA, R. P.; MARENGO, J. A.; PISNITCHENKO, I.; ALVES, L. M. Cenários regionalizados de clima no Brasil para o século XXI: Projeções de clima usando três modelos regionais. Relatório 3, Ministério do Meio Ambiente - MMA, Secretaria de Biodiversidade e Florestas - SBF, Diretoria de Conservação da Biodiversidade - DEBio Mudanças Climáticas - Sub-projeto: Caracterização do clima atual e definição das alterações climáticas para o território brasileiro ao longo do Século XXI. Brasília, 2007.

BARBIERI, J. C.; CAJAZEIRA, J. E. R. Responsabilidade social empresarial e empresa sustentável: da teoria à prática. 2. ed. São Paulo: Saraiva, 2012.

BRASIL. Lei no 6.938, de 31 de janeiro de 1981. Dispõe sobre a Política Nacional do Meio Ambiente, seus fins e mecanismos de formulação e aplicação, e dá outras providências. Diário Oficial [da] República Federativa do Brasil. Brasília, DF. Disponível em: http://www.planalto.gov.br/ccivil 03/Leis/L6938.htm. Acesso em: 26 julho de 2020.

$\begin{array}{llllll}\text { Caminhos de Geografia } & \text { Uberlândia - MG } & \text { v. 22, n.84 } & \text { dez/2021 } & \text { p. 187-199 Página } 198\end{array}$


DIAMANDIS, P.; KOTLER, S. The future is better than you think. Massachusetts: Free Press, 2012. FOLADORI, G. A questão ambiental em Marx. Crítica Marxista. São Paulo: Xamã Editora, v. 1, 1997.

GRIFFIN, M., BABIN, B. J., DARDEN, W. R. Consumer assessments of responsibility for productrelated injuries: The impact of regulations, warnings, and promotional policies. Advances in Consumer Research, 19, 870-878, 1992.

GUIMARÃES, R. The Ecopolitics of Development in the Third World: Politics and Environment in Brazil. Boulder e Londres: Lynne Rienner Publishers, 1991.

INSTITUTO TRATA BRASIL. Saneamento no Brasil: evolução dos serviços de água e esgoto no país (\%). Disponível em: http://www.tratabrasil.org.br/saneamento/principais-estatisticas. Acesso em: 26 de julho de 2020.

IPCC. Climate Change 2013: The Physical Science Basis. Contribution of Working Group I to the Fifth Assessment Report of the Intergovernmental Panel on Climate Change [Stocker, T.F., D. Qin, G.K. Plattner, M. Tignor, S.K. Allen, J. Boschung, A. Nauels, Y. Xia, V. Bex and P.M. Midgley (eds.)]. Cambridge University Press, Cambridge, United Kingdom and New York, NY, USA, 2013, 1535 pp. Disponível em: https://www.ipcc.ch/report/ar5/wg1/. Acesso em: 22 de agosto de 2020.

IPCC. Climate Change 2021: Summary for Policymakers. Contribution of Working Group I to the Sixth Assessment Report of the Intergovernmental Panel on Climate Change [Masson-Delmotte, V., P. Zhai, A. Pirani, S.L. Connors, C. Péan, S. Berger, N. Caud, Y. Chen, L. Goldfarb, M.I. Gomis, M. Huang, K. Leitzell, E. Lonnoy, J.B.R. Matthews, T.K. Maycock, T. Waterfield, O. Yelekçi, R. Yu, and B. Zhou (eds.)]. Cambridge University Press. In Press. Disponível em: https://www.ipcc.ch/report/ar6/wg1/\#SPM. Acesso em: 26 de outubro de 2021.

LIMA, J.E.F.W. Recursos hídricos no Brasil e no mundo. Planaltina: Embrapa Cerrados, 2001. LOMBORG, B. O Ambientalista Cético. Rio de Janeiro: Elsevier, 2002.

MALTHUS, T. R. Ensaio sobre a população. In: Princípios de economia política e considerações sobre sua aplicação prática/Ensaio sobre a população. Coleção "Os economistas". São Paulo: Editora Abril, 1983.

MEADOWS, D. H; MEADOWS, D. L.; RANDERS, J.; BEHRENS III, W. W. Limites do crescimento, São Paulo: Editora Perspectiva, 1973.

MEADOWS, D. H.; RANDERS, J.; MEADOWS, D. L. The limits to growth: the 30-year update. White River Junction, Vt: Chealsea Green Pub. Co, 2004.

NAKICENOVIC, N. et al. Special Report on Emissions Scenarios, Intergovernmental Panel on Climate Change. Cambridge University Press, Cambridge, United Kingdom and New York, 2000, 599 p.

PEZZI, L. P.; SOUZA, R. B.; QUADRO, M. F. L. Uma revisão dos processos de interação oceanoatmosfera em regiões de intenso gradiente termal do Oceano Atlântico Sul baseada em dados observacionais. Revista Brasileira de Meteorologia, v. 31, n. 4, p. 428-453, 2015.

RODRIGUES, M. S. Impactos ambientais urbanos: desafios e perspectivas para a implementação de políticas públicas ambientais no Estado de Pernambuco. 109 f. Dissertação (Mestrado Profissional de Políticas Públicas) - Universidade Federal de Pernambuco, Recife, 2016.

SACHS, I. Ecodesenvolvimento - crescer sem destruir. São Paulo: Vértice, 1986.

SACHS, I. Estratégias de Transição para o século XXI: Desenvolvimento e Meio Ambiente. São Paulo: Studio Nobel, 1993.

TERRABRASILIS. Taxas de desmatamento da Amazônia Legal e incrementos do desmatamento do Cerrado. Disponível em: http://terrabrasilis.dpi.inpe.br/. Acesso em 26 de jul. 2020.

UNITED NATIONS. World Urbanization Prospects 2018: Highlights. Department of Economic and Social Affairs. New York, 2019.

Recebido em: 26/08/2020

Aceito para publicação em: 09/12/2020 